\title{
$\begin{array}{ll}\text { Research Square } & \text { Preprints are preliminary reports that have not undergone peer review. } \\ \text { They should not be considered conclusive, used to inform clinical practice, } \\ \text { or referenced by the media as validated information. }\end{array}$
}

\section{Does hypovitaminosis $A$ in mothers cause congenital malformation of eye?}

MEHUL SHAH ( $\nabla$ omtrustdahod@gmail.com )

DRASHTI NETRALAYA

SHREYA SHAH

DRASHTI NETRALAYA

Ashit Desai

DRASHTI NETRALAYA

Ronuaq Khanna

DRASHTI NETRALAYA

Chetan Rathod

DRASHTI NETRALAYA

\section{Short Report}

Keywords: Congenital malformation of eye, hypovitaminosis vitamin A

Posted Date: August 19th, 2020

DOI: https://doi.org/10.21203/rs.3.rs-60299/v1

License: (c) (1) This work is licensed under a Creative Commons Attribution 4.0 International License.

Read Full License

Version of Record: A version of this preprint was published at Acta Scientific Ophthalmology on October 7th, 2020. See the published version at https://doi.org/10.31080/ASOP.2020.03.0174. 


\section{Abstract}

Introduction: Congenital malformation is important cause of child hood blindness, we would like to study factors responsible for it.

Methods: This was retrospective cohort study We collected data from our hospital EMR from 2008 to 2019.WE retrieved total number of Pediatric patients outdoor and children with congenital malformed eyes. We also explored history of night blindness in mothers during pregnancy we exported data in excel sheet, type of anomalies calculated using descriptive analyses of SPSS 22.

Results: Our cohort consisted of 1435(1.42\%) children out of 100946 of total outdoor of pediatric ophthalmology. We found various anomalies in our analyses, out of total $423(29.47 \%)$ had history of night blindness to mother during pregnancy suggesting vitamin A deficiency.

Conclusion: Hypovitaminosis A in mother has influence maldevelopment and congenital anomalies of eye based on clinical observation.

\section{Introduction}

Blindness in children causes a deep impact on the psychological, emotional, and socioeconomic growth of the family. It has been observed that unlike adult blindness, which is $80 \%$ avoidable (either preventable or treatable), only less than $50 \%$ of the causes are preventable in children. The prevalence globally has been reported to be as high as 1.5 per 1000 children in contrast to the high-income countries where the figure is only 0.3 per $1000[1,2]$.

As the prevalence of blindness in children is relatively lower than that in adults, a large sample size is required to provide accurate data on the occurrence and causes of childhood blindness. The current rate is known to be $0.8 / 1000[3,4]$. The studies from India have shown that there has been an overall increase in congenital globe anomalies over the past two decades, and recent investigations have asserted that the condition contributes to nearly $40 \%$ of all causes of Childhood blindness $[1,2,3,4]$. To tackle the current causes of ocular morbidity attributed to whole globe and retinal abnormalities, a careful genetic counselling of parents before childbirth is necessary.

In India, 3,20,000 children ( $<16$ years) are blind, which constitutes $1 / 5^{\text {th }}$ of the world's blind children [4]. As reported by Dandona et al. [3], the prevalence of blindness is $0.17 \%$ in Andhra Pradesh, which corresponds to $6,80,000$ children (after extrapolation) (Vision 20202).

The prevalence of childhood blindness was found to be $0.17 \%$ ( $95 \%$ confidence interval $0.09-0.30$ ). Treatable refractive error caused $33.3 \%$ of the blindness, followed by $16.6 \%$ resulting from preventable causes ( $8.3 \%$ each due to vitamin A deficiency and amblyopia after cataract surgery). The other major causes included congenital eye anomalies (16.7\%) and retinal degeneration (16.7\%) [3]. 
Upon examining the etiological causes, childhood disorders (mainly corneal infections) as a cause of blindness have declined in the Southern part of the country but are still prevalent in the North and Northeastern parts (especially in the rural pockets) $[1,2]$. Data also indicate that congenital anomalies and retinal causes are increasing in certain regions of the country $[1,2]$.

However, the etiology is still not known for a majority of the causes (Khanna).

\section{Methods}

After obtaining approval from the Hospital Ethical Committee, we retrieved data from the Electronic Medical Records pertaining to the period 2008-2019. All children with congenital malformation were enlisted, and all information regarding the type of anomalies, family history, maternal history, and birth history of the child were acquired. Specifically, details regarding night blindness in mothers during the last trimester of pregnancy was collected. We documented the total number of fresh outdoor cases, number of children having congenital malformation of the eye, and mothers experiencing night blindness during the last trimester.

\section{Results}

Our cohort consisted of 1435 cases. We found that--children were totally examined at the Department of Paediatric Ophthalmology, of which 1435 (\%) children exhibited congenital malformation of the eye. Out of the $1423(29.47 \%)$ children having a history of night blindness in mothers, 1330 (92.7\%) were total globe anomalies and only 105 (7.3\%) constituted other anomalies. We encountered $250(17.4 \%)$ choroidal colobomas, $174(12.1 \%)$ iris colobomas, 248 (17.3\%) microcornea, 212 (14.8\%) microphthalmos, 236 (16.4\%) cryptophthalmos, 83(5.7\%) enophthalmos, and 306 (21.3\%) retinal degeneration and other anomalies such as hypertelorism, congenital optic atrophy, and persistent hyperplastic primary vitreous (PHPV)(Table1).

\section{Discussion}

Congenital malformation of the eye is an important cause of childhood blindness. We had $29.47 \%$ mothers with a history of night blindness during pregnancy, which is suggestive of hypovitaminosis $\mathrm{A}$. Many clinical studies have covered congenital malformation of the eye and its relationship with hypovitaminosis A. Many experimental studies have suggested that hypovitaminosis and folic acid deficiencies in mother leads to congenital malformations of the eye.

Mastereo-de-las et al. have reported that mice exposed to a folic acid-deficient diet demonstrated numerous macroscopic eye anomalies, such as anophthalmia and microphthalmia. Microscopically too, the eye was the most affected organ (43.7\% of the fetuses) [5].

Yomai et al. have documented that several putative genetic and environmental causes are associated with microphthalmia and anophthalmia, including vitamin A deficiency [6]. 
Bhattacharrji et al. and Millemann et al. have stated that the major anatomical causes of visual loss amongst 93 of the 258 patients (36.1\%) were congenital anomalies (anophthalmos and microphthalmos) [7].

Horneby asserted the presence of epidemiological and laboratory evidence supporting a hypothesis of genetic (recessive) predisposition to the teratogenic effects of mild-to-moderate maternal vitamin $A$ deficiency during pregnancy. This fact may explain the high prevalence of congenital eye anomalies in certain Asian countries where maternal deficiency of the vitamin is common and consanguineous marriages are popular. Besides, other congenital malformations commonly found in association with ocular coloboma (e.g. Esophageal fistulae and heart defects in CHARGE association) might also be related to the deficiency [8].

The results revealed that $43 \%$ of the parents were consanguineous, $19 \%$ had a positive family history, and that the frequency of coloboma was the highest in the second-born children. Eleven (16\%) mothers had a history of night blindness while they were pregnant with the affected child, $7(8 \%)$ had consumed medication during the first trimester (abortifacients in two cases), $3 \%$ had reported fever in the first trimester, and 11 (13\%) had exposure to agricultural chemicals [8].

According to Ward et al., during embryogenesis, information encoded in the genome is translated into cell proliferation, morphogenesis, and early stages of differentiation. Embryonic pattern arises from the spatial and temporal regulation and coordination of these events. The vitamin A (retinol) derivative, retinoic acid (RA), is essential for normal development. Mammalian embryos are protected against vitamin A deficiency by maternal retinoid homeostasis until the stored retinoids fall to very low levels. Retinol binding protein, which is synthesized in the yolk sac placenta of rodent embryos and in the syncytiotrophoblast of the human placenta, is imperative for the embryo to access retinol. Synthesis and metabolism of RA may involve cytoplasmic binding proteins, but the observation that mutants lacking these proteins are normal or near-normal suggests that they are not essential. Severe congenital vitamin A deficiency results in a spectrum of malformations, including defects of the eyes, lungs, cardiovascular system, and urogenital system [9].

Many other studies have also reported similar findings either in clinical or in animal studies [10-16].

\section{Declarations}

Ethics and Consent: Patient and parental consent was obtained for minor and approval from hospital ethical committee also was obtained approval no is $\mathrm{dn} / 23 / 2020$

\section{References}

1. Wadhwani M, Vashist P, Singh SS, Gupta V, Gupta N,Saxena R. Prevalence and causes of childhood blindness in India: A systematic review. Indian J Ophthalmol 2020;68:311-5 
2. Khanna RC. Commentary: Childhood blindness in India:Regional variations. Indian J Ophthalmol 2018;66:1461-2.

3. R Dandona, L Dandona Childhood blindness in India: a population based perspective $\mathrm{Br} \mathrm{J}$ Ophthalmol 2003;87:263-265

4. G V S Murthy, MD; Sanjeev K Gupta, MD; Neena John, MCA; Praveen Vashist, MD Current status of cataract blindness and Vision 2020: The right to sightinitiative in India Indian Journal of Ophthalmology :2008; 56 489-94

5. Maestro-de-las-Casas, C., J. Perez-Miguelsanz, et al. "Maternal folic acid-deficient diet causes congenital malformations in the mouse eye." Birth Defects Res A Clin Mol Teratol 97(9): 587-96.

6. Yomai, A. A. and B. I. Pavlin "Microphthalmia and anophthalmia in Chuuk State, Federated States of Micronesia." Pac Health Dialog 16(1): 141-4.

7. Bhattacharjee, H., K. Das, et al. "Causes of childhood blindness in the northeastern states of India." Indian J Ophthalmol 2008;56(6): 495-9.

8. Millemann, Y., H. Benoit-Valiergue, et al. "Ocular and cardiac Bhattacharjee malformations associated with maternal hypovitaminosis A in cattle." 2007; Vet Rec 160(13): 441-3.

9. Hornby, S. J., S. J. Ward, et al. "Eye birth defects in humans may be caused by a recessively-inherited genetic predisposition to the effects of maternal vitamin A deficiency during pregnancy." Med Sci Monit 2003;9(11): HY23-6.

10. Hornby, S. J., S. J. Ward, et al. "Environmental risk factors in congenital malformations of the eye." Ann Trop Paediatr 2002; 22(1): 67-77.

11. Morriss-Kay, G. M. and N. Sokolova (1996). "Embryonic development and pattern formation." Faseb J 10(9): 961-8.

12. Palludan, B. "The influence of vitamin A deficiency on foetal development in pigs with special reference to eye organogenesis." Int J Vitam Nutr Res 1976|46(2): 223-5.

13. Giroud, A., C. Roux, et al. "[Congenital ocular abnormalities in vitamin A deficiency]." Ann Ocul (Paris). 195: 566-7.

14. Roux, C., P. Fournier, et al. (1962). "[Congenital ocular anomalies in vitamin A deficiency]." Bull Soc Ophtalmol Fr 1962 62: 12-21.

15. Giroud, A., A. Delmas, et al.Fetal eye malformations of the folic acid deficient rat]." Arch Anat Microsc Morphol Exp 1954; 43(1): 21-41.

16. Warkany, J. and E. Schraffenberger "Congenital malformations induced in rats by maternal vitamin A deficiency; defects of the eye." Arch Ophthal 1946;35: 150-69.

\section{Table}

Table-1 DISTRIBUTION OF TYPE OF CONGENITAL ANOMALIES 


\begin{tabular}{|lll|}
\hline TYPE OF ANOMALY & NUMBER & PERCENTAGE(\%) \\
\hline IRIS COLOBOMA & 174 & 12.1 \\
\hline ENOPHTHALMOS & 66 & 4.6 \\
\hline MICROCORNEA & 248 & 17.3 \\
\hline MICROOPTHALMOS & 212 & 14.8 \\
\hline RETINAL DEGENERATIONS & 306 & 21.3 \\
\hline CRYPTOPHTHALMOS & 17 & 1.2 \\
\hline CHOROIDAL COLOBOMA & 250 & 17.4 \\
\hline PHPV & 18 & 1.3 \\
\hline CONGENITAL OPTIC ATROPHY & 27 & 1.9 \\
\hline OTHER & 117 & 8.1 \\
\hline TOTAL & 1435 & 100 TYPE OF ANOMALIES \\
\hline
\end{tabular}

